\title{
Effect of insemination after estrous detection on pregnancy per artificial insemination and pregnancy loss in a Presynch-Ovsynch protocol: A meta-analysis
}

\author{
S. Borchardt, P. Haimerl, and W. Heuwieser ${ }^{1}$ \\ Clinic for Animal Reproduction, Faculty of Veterinary Medicine, Freie Universität Berlin, Koenigsweg 65, 14163 Berlin, Germany
}

\begin{abstract}
Presynchronization of cows with 2 injections of prostaglandin administered $14 \mathrm{~d}$ apart (Presynch-Ovsynch) is a widely adopted procedure to increase pregnancy per artificial insemination (P/AI) for the first service. In a Presynch-Ovsynch protocol, 2 different management strategies can be observed. Either all cows receive timed artificial insemination (onlyTAI) or cows detected in estrus after the second $\mathrm{PGF}_{2 \alpha}$ injection are inseminated and the remaining cows without signs of estrus will be subject to timed AI (EDAI+TAI). A systematic review of the literature was performed with the objective to evaluate the effect of insemination after estrous detection during a Presynch-Ovsynch protocol for the first service on fertility in lactating dairy cows. Two statistical approaches were conducted using either a fixed or a random effects meta-analysis based on the heterogeneity among the experimental groups. Reproductive outcomes of interest were P/AI measured on d 32 (d 28 to 42 ) and pregnancy loss between d 32 and 60 (d 42 to 74 ) of gestation. In approach 1, 3 randomized controlled studies including 1,689 cows with the primary objective to evaluate the effect of insemination after estrous detection in a Presynch-Ovsynch protocol were used. The incorporation of insemination after estrous detection decreased the odds of pregnancy by $35 \%$ [odds ratio $=0.65 ; 95 \%$ confidence interval $(\mathrm{CI})=$ 0.53-0.80] on d 32 after AI using a fixed effects model. We detected no effect on pregnancy loss on d 60 of gestation (odds ratio $=0.88 ; 95 \% \mathrm{CI}=0.55-1.43$ ). There was no heterogeneity among the 3 studies regarding $\mathrm{P} / \mathrm{AI}$ and pregnancy loss. In approach 2, cows from approach 1 and cohorts from another 17 experimental groups including 8,124 cows submitted to first AI using a Presynch-Ovsynch protocol were used. Information regarding pregnancy loss was available for 5,200 cows. In the random effects model, the overall proportion of $\mathrm{P} / \mathrm{AI}$ was $30.9 \%(95 \% \mathrm{CI}=26.71-35.28 ; \mathrm{n}=2,400)$
\end{abstract}

Received September 7, 2015.

Accepted November 20, 2015.

${ }^{1}$ Corresponding author: w.heuwieser@fu-berlin.de and $41.7 \%(95 \% \mathrm{CI}=39.76-42.01 ; \mathrm{n}=7,413)$ on $\mathrm{d}$ 32 after AI for EDAI+TAI and onlyTAI, respectively. The overall proportion of pregnancy loss was $11.7 \%$ $(95 \% \mathrm{CI}=6.11-18.8 ; \mathrm{n}=1,811)$ and $9.6 \%(95 \% \mathrm{CI}=$ $6.37-13.33 ; \mathrm{n}=3,389)$ on d 60 after AI for EDAI+TAI and onlyTAI, respectively. We observed substantial heterogeneity among the experimental groups regarding $\mathrm{P} / \mathrm{AI}$ and pregnancy loss. In summary, there was a benefit on P/AI for cows with 100\% TAI after completing a Presynch-Ovsynch protocol.

Key words: presynchronization, estrous detection, meta-analysis

\section{INTRODUCTION}

Synchronization protocols for timed artificial insemination (TAI) have been widely adopted in the dairy industry to improve reproductive performance (Caraviello et al., 2006). Initially, these programs consisted of systematic applications of $\mathrm{GnRH}$ and $\mathrm{PGF}_{2 \alpha}$ with the aim of increasing primarily the insemination risk and not necessarily the risk of conception (Pursley et al., 1995). Therefore, several methods have been evaluated to improve fertility to TAI (Wiltbank and Pursley, 2014). Among them, presynchronization with 2 doses of $\mathrm{PGF}_{2 \alpha}$ administered $14 \mathrm{~d}$ apart has been shown to improve pregnancy per artificial insemination $(\mathbf{P} / \mathbf{A I})$ after TAI in several studies (Moreira et al., 2001; ElZarkouny et al., 2004; Navanukraw et al., 2004). This program, known as "Presynch-Ovsynch" (PO), has become popular. In a survey of reproductive elite herds in the United States, the majority (15/16) implemented PO for the first service (Ferguson and Skidmore, 2013). The PO program is intended to ensure that cows are at the most appropriate stage of the estrous cycle at the time of the first GnRH treatment for the TAI by ovulating a follicle after GnRH treatment (El-Zarkouny et al., 2004). This was shown to be positively associated with conception rate after TAI (Vasconcelos et al., 1999). While improving $\mathrm{P} / \mathrm{AI}$ after TAI, the PO protocol also introduces some flexibility in allowing insemination on estrus for herd managers that decide not to time-inseminate every cow (Chebel and Santos, 
2010). Therefore, in a PO protocol, 2 different management strategies can be observed. Either all cows are time-inseminated (onlyTAI) or cows detected in estrus after the second $\mathrm{PGF}_{2 \alpha}$ injection are inseminated and the remaining cows without signs of estrus will be subject to TAI (EDAI+TAI; Fricke et al., 2014). Recent studies have shown that approximately 50 to $70 \%$ of cows presynchronized with 2 injections of $\mathrm{PGF}_{2 \alpha}$ were inseminated based on estrous detection before the completion of the TAI protocol (Stevenson and Phatak, 2005; Chebel and Santos, 2010; Fricke et al., 2014). There are conflicting reports on the effects of estrous detection in TAI protocols on P/AI. Some authors showed a positive effect on $\mathrm{P} / \mathrm{AI}$ for cows with onlyTAI compared with EDAI+TAI (Gumen et al., 2012; Fricke et al., 2014), whereas others did not (Stevenson and Phatak, 2005; Chebel and Santos, 2010). Additionally, there was no economic difference between onlyTAI and EDAI+TAI (Chebel and Santos, 2010; Fricke et al., 2014). The latter was due to a tradeoff between DIM at first service and P/AI. It was assumed, however, that maximum $\mathrm{P} / \mathrm{AI}$ can be achieved with onlyTAI in a $\mathrm{PO}$ protocol (Fricke et al., 2014).

Individual studies often encompass a limited number of herds with similar management practices. Therefore, this meta-analysis was designed to evaluate the effects of insemination after estrous detection during a PO protocol across different managerial conditions. The main hypothesis of the present study is that the maximum effect on $\mathrm{P} / \mathrm{AI}$ in a $\mathrm{PO}$ protocol for the first service would be achieved by neglecting estrous detection after the second PGF injection.

\section{MATERIALS AND METHODS}

\section{Literature Search}

The literature search was conducted in PubMed (http://www.ncbi.nlm.nih.gov/pubmed), ScienceDirect (http://www.sciencedirect.com), and Google Scholar (http://scholar.google.com) using the search terms "dairy cow AND presynchronization." A total of 59, 230, and 1,580 results were obtained in each search engine, respectively. Additional manuscripts were obtained directly from researchers in the field of reproductive biology. Results from the online search and personal communications were assessed individually for the initial screening to be considered for the meta-analysis.

\section{Inclusion and Exclusion Criteria}

We considered only randomized studies using a presynchronization for the first service with 2 applications of $\mathrm{PGF}_{2 \alpha} 14 \mathrm{~d}$ apart followed by an Ovsynch protocol for TAI as described elsewhere (Pursley et al., 1995) with minor modifications. The time interval between the $\mathrm{PGF}_{2 \alpha}$ injection and the $\mathrm{GnRH}$ injection in the Ovsynch protocol had to range from 48 to $56 \mathrm{~h}$. The time interval from the last $\mathrm{GnRH}$ injection in the Ovsynch protocol until timed AI had to range from 12 to $20 \mathrm{~h}$. Hence, studies using another protocol for timed AI (e.g., CoSynch72, 5d-CoSynch) were not included. The time interval between the second injection of $\mathrm{PGF}_{2 \alpha}$ and the first $\mathrm{GnRH}$ injection from the Ovsynch protocol ranged from 9 to $14 \mathrm{~d}$. We identified 3 randomized controlled studies directly evaluating the effect of AI following estrous detection in a $\mathrm{PO}$ protocol (Chebel and Santos, 2010; Gumen et al., 2012; Fricke et al., 2014).

Based on these criteria, the meta-analysis included a total of 20 articles including 9,813 cows presynchonized using a PO protocol for first AI. Of these, 17 manuscripts described studies conducted with high-producing cows under confinement housing in the United States, 1 in Canada, 1 in Turkey, and 1 in Mexico.

\section{Data Extraction}

Data extraction was performed by a single investigator (S. Borchardt) and validated by a coauthor (W. Heuwieser). For each study, recorded information included authors, year of publication, number of herds, sample size calculation, stratification of results by parity, $\mathrm{PGF}_{2 \alpha}$ product and dose, DIM at first $\mathrm{PGF}_{2 \alpha}$ injection, time interval between second $\mathrm{PGF}_{2 \alpha}$ injection and first GnRH injection of the Ovsynch protocol, time schedule of the Ovsynch protocol, DIM at TAI, insemination of cows in estrus during the timed AI protocol, and time of pregnancy examination (Tables 1 and 2).

Experimental groups were classified regarding their management of first service. The EDAI+TAI group consisted of experimental groups, where cows with estrus symptoms after the second PGF injection were inseminated and the remaining cows showing no estrus symptoms were time-inseminated. For these experimental groups, the voluntary waiting period was set at the same day as the second $\mathrm{PGF}_{2 \alpha}$ injection. The onlyTAI group consisted of experimental groups, where cows were only inseminated on the day of timed AI. The voluntary waiting period ended at the same day when timed AI was performed.

Pregnancy status was evaluated twice after AI, except for 7 manuscripts. The ranges for the first (PD1) and second pregnancy diagnoses (PD2) were 28 to 42 and 42 to $74 \mathrm{~d}$ after AI, respectively. For simplicity, the time at which pregnancy was evaluated for the first and second time will be referred to as d 32 and d 60 after AI throughout the manuscript, respectively. Reproductive 
Table 1. Summary of manuscripts $(n=20)$ using a Presynch-Ovsynch protocol for the first AI considering evaluated information criteria

\begin{tabular}{|c|c|c|c|c|c|c|c|c|}
\hline Reference & Country & $\begin{array}{l}\text { Milk yield, } \\
\mathrm{kg}^{1}\end{array}$ & No. of AI & No. of herds & Random & $\begin{array}{l}\text { Sample size } \\
\text { calculated }^{2}\end{array}$ & $\begin{array}{c}\text { Parity } \\
\text { considered }\end{array}$ & $\begin{array}{c}\text { Pregnancy loss } \\
\text { calculated }\end{array}$ \\
\hline Bicalho et al., 2007 & USA & $\mathrm{NA}^{3}$ & 399 & 5 & Yes & $\mathrm{No}$ & $\mathrm{No}$ & $\mathrm{No}$ \\
\hline Bruno et al., 2013 & USA & 38 & 552 & 1 & Yes & Yes & No & Yes \\
\hline Chebel and Santos, 2010 & USA & 12,035 & 639 & 1 & Yes & Yes & No & Yes \\
\hline Chebel et al., 2006 & USA & $35 / 48$ & 338 & 1 & Yes & Yes & No & Yes \\
\hline Colazo et al., 2013 & Canada & 10,370 & 241 & 1 & Yes & No & Yes & Yes \\
\hline Gumen et al., 2012 & Turkey & 9,800 & 385 & 1 & Yes & No & No & Yes \\
\hline Herlihy et al., 2012 & USA & NA & 850 & 3 & Yes & Yes & Yes & Yes \\
\hline Melendez et al., 2006 & Mexico & 13,790 & 589 & 1 & Yes & Yes & No & No \\
\hline Moreira et al., 2001 & USA & NA & 269 & 1 & Yes & No & No & Yes \\
\hline Navanukraw et al., 2004 & USA & 39 & 135 & 1 & Yes & No & No & No \\
\hline Poock et al., 2015 & USA & 10,925 & 1,790 & 1 & Yes & No & Yes & No \\
\hline Overall & & & 9,813 & 27 & $20 / 20$ & $5 / 20$ & $4 / 20$ & $13 / 20$ \\
\hline
\end{tabular}

${ }^{1}$ Milk yield of the study population either presented as rolling herd average or average daily milk yield for the study period.

${ }^{2}$ An a priori sample size calculation was performed.

${ }^{3} \mathrm{NA}=$ not available.

Table 2. Description of reproductive management in 24 experimental groups using a Presynch-Ovsynch protocol for first service $(\mathrm{n}=9,813)$

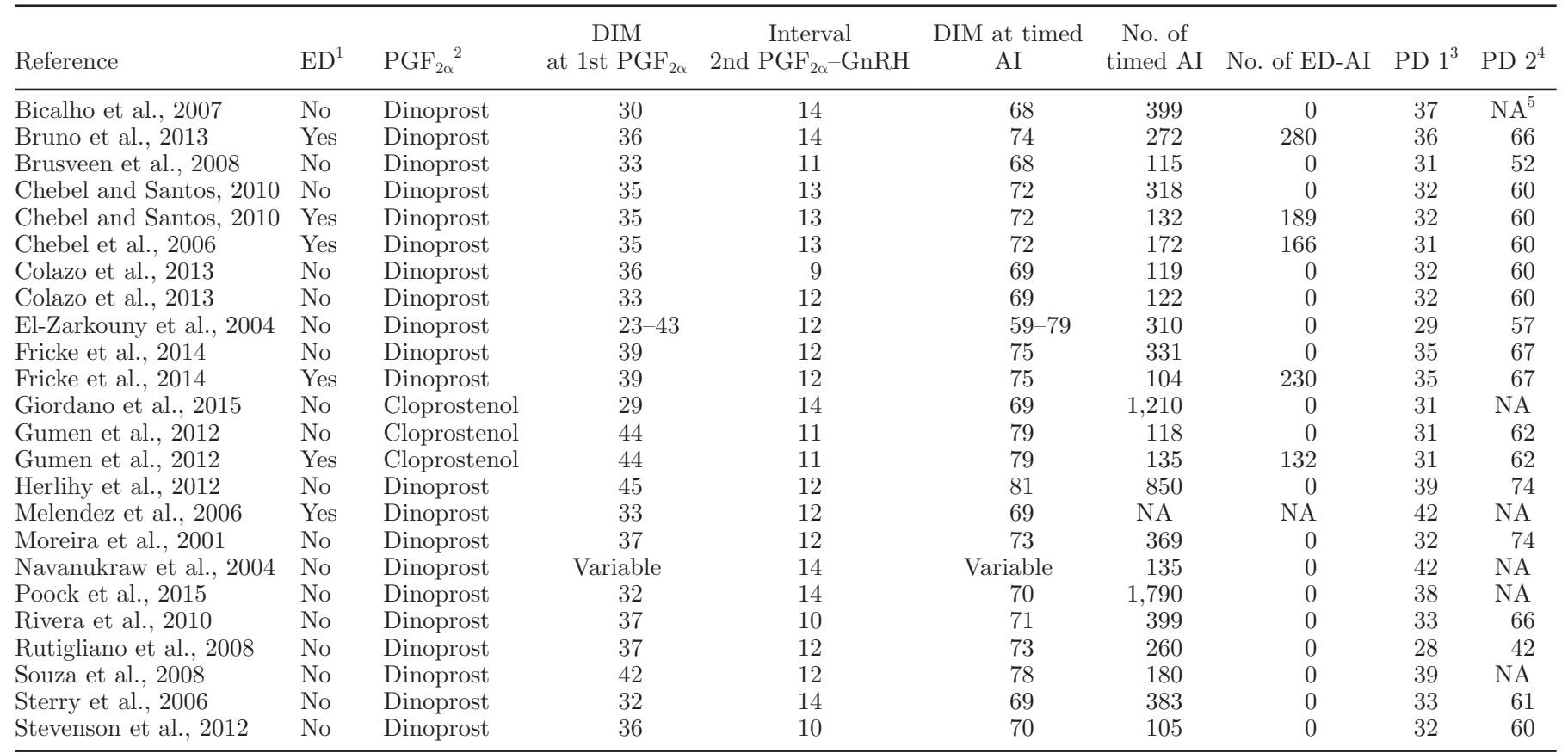

${ }^{1} \mathrm{ED}=$ estrous detection and $\mathrm{AI}$ after presynchronization.

${ }^{2} \mathrm{PGF}_{2 \alpha}$ was either dinoprost $(25 \mathrm{mg})$ or cloprostenol $(500 \mu \mathrm{g})$.

${ }^{3}$ Days after AI for the first pregnancy diagnosis (PD).

${ }^{4}$ Days after AI for the second pregnancy diagnosis.

${ }^{5} \mathrm{NA}=$ not available. 
outcomes were $\mathrm{P} / \mathrm{AI}$ on $\mathrm{d} 32$ and pregnancy loss on $\mathrm{d}$ 60 . Within the study, P/AI was calculated as the number of cows diagnosed pregnant on d 32 after AI divided by the total number of cows inseminated. Pregnancy loss was calculated as the number of cows diagnosed pregnant on $\mathrm{d} 32$ that lost the pregnancy before $\mathrm{d} 60$ divided by the number of cows diagnosed pregnant on d 32. Experimental groups in which a single pregnancy diagnosis was performed were not included in the analysis of pregnancy loss.

\section{Statistical Analyses}

The meta-analysis was conducted using MedCalc software (version 15.6.1, MedCalc, Mariakerke, Belgium). We conducted 2 different approaches for evaluating the effect of insemination after estrous detection in a timed AI program.

Approach 1: Three Manuscripts with a Randomized Controlled Study Design. There were 3 manuscripts with 1,689 AI directly evaluating the effect of estrous detection on $\mathrm{P} / \mathrm{AI}$ and pregnancy loss in a PO protocol using a randomized controlled study design (Chebel and Santos, 2010; Gumen et al., 2012; Fricke et al., 2014). Cows that were only allowed to be time-inseminated without estrous detection (onlyTAI) served as the control group. We calculated an odds ratio (OR) for conceiving at first $\mathrm{AI}$ and losing pregnancy on d 60 using a fixed effects and a random effects model. Under the fixed effects model, it is assumed that all experimental groups come from a common population, and that the effect size is not significantly different among the different trials as described by the heterogeneity $\left(\boldsymbol{I}^{2}\right)$. However, if there is a significant heterogeneity, the random effects model may be more appropriate, in which both the random variation within the experimental group and the variation between the different experimental groups is incorporated (Borenstein et al., 2009). MedCalc uses the Mantel-Haenszel method for calculating the weighted summary OR under the fixed effects model. The heterogeneity statistic is incorporated to calculate the summary OR under the random effects model (DerSimonian and Laird, 1986).

Heterogeneity $\left(I^{2}\right)$ is the percentage of observed total variation across studies that is due to real heterogeneity rather than chance. It is calculated as follows: $I^{2}$ $=100 \% \times(\mathrm{Q}-\mathrm{df}) / \mathrm{Q}$, where $\mathrm{Q}$ is Cochran's heterogeneity statistic and df is the degrees of freedom. Negative values of $I^{2}$ are made equal to zero so that $I^{2}$ lies between 0 and $100 \%$. A value of $0 \%$ indicates no observed heterogeneity, and larger values show increasing heterogeneity (Higgins et al., 2003).

Approach 2: All 24 Experimental Groups. For the second approach, we included 24 experimental groups with information on $\mathrm{P} / \mathrm{AI}$ for 9,813 $\mathrm{AI}$ and 17 experimental groups with information on pregnancy loss for 1,986 pregnancies from first service. Most of them were not designed to evaluate the effect of estrous detection in a timed AI program. Therefore, a direct comparison of $\mathrm{P} / \mathrm{AI}$ and pregnancy losses in onlyTAI and EDAI+TAI cows, as in approach 1, was not possible. However, to determine the effect size of P/AI, we calculated the pooled proportion from the 18 experimental groups using onlyTAI and the 6 experimental groups using EDAI+TAI. For the effect size of pregnancy loss, we calculated the pooled proportion from the 12 experimental groups using onlyTAI and the 5 experimental groups using EDAI+TAI with information on pregnancy loss. The pooled proportion is an overall estimate of the effect for $\mathrm{P} / \mathrm{AI}$ or pregnancy loss that takes into account both the individual estimate and its precision for the experimental group.

The pooled proportions with their 95\% CI under the fixed and the random effects model were compared. MedCalc uses a Freeman-Tukey transformation (Freeman and Tukey, 1950) to calculate the weighted summary proportion under the fixed and random effects model (DerSimonian and Laird, 1986). We reported the pooled proportion from the random effects model when $I^{2}$ was significant $(P \leq 0.05)$.

The overall proportion of $\mathrm{P} / \mathrm{AI}$ for onlyTAI and EDAI+TAI under the fixed and the random effects model for EDAI+TAI and onlyTAI were presented separately with the $95 \%$ CI.

\section{RESULTS}

\section{Approach 1: Manuscripts with a Randomized Controlled Study Design}

Three manuscripts had a randomized controlled study design, with a total of 1,689 AI evaluating the effect of estrous detection in a $\mathrm{PO}$ protocol on $\mathrm{P} / \mathrm{AI}$ (Table 3) and pregnancy loss. The incorporation of estrous detection into a PO protocol decreased $(P<$ $0.01)$ the odds of pregnancy $(\mathrm{OR}=0.65 ; 95 \% \mathrm{CI}=$ $0.53-0.80$ ) in lactating dairy cows on d 32 after AI using the fixed effects model. Based on the raw data, the difference in P/AI between onlyTAI and EDAI+TAI was 8.8 percentage units on d $32(42.1$ vs. $33.3 \%)$ after AI. The pooled estimate for $\mathrm{P} / \mathrm{AI}$ was $32.5 \%(179 / 551)$ and $34.5 \%$ (128/371) for cows inseminated after detected estrus and cows receiving TAI that were not seen in estrus after the second PGF injection in the EDAI+TAI group, respectively. There was no heterogeneity $\left(I^{2}=\right.$ $48.7 \% ; P=0.1423$ ) among the 3 studies regarding $\mathrm{P} /$ AI. However, the 95\% CI for the individual studies varied noticeably, with one study (Chebel and Santos, 
Table 3. Effect of estrous detection on pregnancy per AI (P/AI) in a Presynch-Ovsynch protocol for the first service $(\mathrm{n}=1,689)$ considering 3 manuscripts with a controlled study design

\begin{tabular}{|c|c|c|c|c|c|}
\hline Reference & $\begin{array}{c}\text { EDAI+TAI } \\
\text { P/AI }\end{array}$ & $\begin{array}{l}\text { OnlyTAI } \\
\text { P/AI }\end{array}$ & Odds ratio ${ }^{1}$ & $95 \%$ CI & $P$-value \\
\hline Chebel and Santos, 2010 & $106 / 321$ & $126 / 318$ & 0.751 & $0.544-1.038$ & \\
\hline Fricke et al., 2014 & $105 / 334$ & $131 / 331$ & 0.700 & $0.509-0.963$ & \\
\hline $\begin{array}{l}\text { Gumen et al., } 2012 \\
I^{2}=48.7 \%^{2}(P=0.1423)\end{array}$ & $96 / 267$ & $66 / 118$ & 0.442 & $0.285-0.688$ & \\
\hline Total (fixed effects) & $307 / 922$ & $323 / 767$ & 0.654 & $0.535-0.800$ & 0.001 \\
\hline Total (random effects) & $307 / 922$ & $323 / 767$ & 0.637 & $0.478-0.849$ & 0.002 \\
\hline
\end{tabular}

2010) indicating no effect of estrous detection in a PO protocol on $\mathrm{P} / \mathrm{AI}$.

The incorporation of estrous detection in a PO protocol had no effect on pregnancy loss $(\mathrm{OR}=0.88 ; 95 \%$ $\mathrm{CI}=0.55-1.43 ; P=0.619)$ in lactating dairy cows on d 60 after AI using the fixed effects model. There was no heterogeneity $\left(I^{2}=50.9 \% ; P=0.1302\right)$ among the 3 studies regarding pregnancy loss.

\section{Approach 2: Effect of Al After Estrous Detection in a PO Protocol on P/AI Including all Experimental Groups}

The EDAI+TAI group consisted of 6 experimental groups with 2,400 AI using estrous detection in a PO protocol for the first service (Table 4 and Figure 1). The overall proportion of $\mathrm{P} / \mathrm{AI}$ was $30.9 \%$ (95\% CI $=26.71-35.28)$ on d 32 after AI for EDAI+TAI. Substantial heterogeneity $\left(I^{2}=80.9 \% ; P=0.0001\right)$ was found among the experimental groups regarding $\mathrm{P} / \mathrm{AI}$. Excluding the study of Melendez et al. (2006) improved homogeneity $\left(I^{2}=0.0 \% ; P=0.4404\right)$ and resulted in an increased overall proportion of $\mathrm{P} / \mathrm{AI}(\mathrm{n}=1,811 ; \mathrm{P} /$ $\mathrm{AI}=32.8 \% ; 95 \% \mathrm{CI}=30.67-35.04$ ).

The onlyTAI group consisted of 18 experimental groups with 7,413 AI not using estrous detection in a PO protocol for the first service (Table 5). The overall proportion of $\mathrm{P} / \mathrm{AI}$ was $41.7 \%$ (95\% CI $=39.76-42.01$ ) on d 32 after AI for onlyTAI. There was substantial heterogeneity $\left(I^{2}=76.1 \% ; P=0.0001\right)$ among the experimental groups regarding $\mathrm{P} / \mathrm{AI}$. The individual proportion of $\mathrm{P} / \mathrm{AI}$ on $\mathrm{d} 32$ after $\mathrm{AI}$ in the experimental groups ranged from $31.9 \%(95 \% \mathrm{CI}=23.68-41.10$; Colazo et al., 2013) to $55.9 \%$ (95\% CI $=46.50-65.06$; Gumen et al., 2012). We could not identify a plausible classification of subgroups in these experimental groups to reduce the amount of heterogeneity considerably. We observed, however, more extreme results in smaller experimental groups, indicating no publication bias.

Based on the random effects model, the difference in $\mathrm{P} / \mathrm{AI}$ between onlyTAI and EDAI+TAI was 10.8 percentage units on d 32 (41.7 vs. $30.9 \%)$ after AI. The $95 \%$ CI for the overall proportion of $\mathrm{P} / \mathrm{AI}$ for EDAI+TAI and onlyTAI did not overlap (Figure 1).

\section{Approach 2: Effect of Al After Estrous Detection in a PO Protocol on Pregnancy Loss Including all Experimental Groups}

For the evaluation of pregnancy loss in the EDAI+TAI group, 5 experimental groups were included, with 1,811 AI resulting in 593 pregnancies (Table 6). The overall proportion of pregnancy loss was $11.7 \%$ (95\% CI = 6.11-18.8) on d 60 after AI for EDAI+TAI. There was

Table 4. Pregnancy per AI (P/AI) in 6 experimental groups including 2,400 AI using estrous detection in a Presynch-Ovsynch protocol for the first service (EDAI+TAI)

\begin{tabular}{lcccc}
\hline Reference & No. pregnant & No. of AI & P/AI $(\%)$ & $95 \%$ CI \\
\hline Bruno et al., 2013 & 188 & 552 & 34.058 & $30.108-38.179$ \\
Chebel and Santos, 2010 & 106 & 321 & 33.022 & $27.899-38.461$ \\
Chebel et al., 2006 & 99 & 338 & 29.290 & $24.491-34.456$ \\
Fricke et al., 2014 & 105 & 333 & 31.532 & $26.575-36.820$ \\
Gumen et al., 2012 & 96 & 267 & 35.955 & $30.197-42.029$ \\
Melendez et al., 2006 & 134 & 589 & 22.750 & $19.424-26.353$ \\
$I^{2}=80.9 \%{ }^{1}(P=0.0001)$ & & & & \\
Total (fixed effects) & & 2,400 & 30.269 & $28.437-32.148$ \\
Total (random effects) & & 2,400 & 30.916 & $26.712-35.284$ \\
\hline
\end{tabular}

${ }^{1} I^{2}=$ proportion of total variation of effect size estimates that is due to heterogeneity. 
Table 5. Pregnancy per AI (P/AI) in 18 experimental groups including 7,413 AI using only timed AI (onlyTAI) in a Presynch-Ovsynch protocol for the first service

\begin{tabular}{|c|c|c|c|c|}
\hline Reference & No. pregnant & No. of AI & $\mathrm{P} / \mathrm{AI}(\%)$ & $95 \% \mathrm{CI}$ \\
\hline Bicalho et al., 2007 & 154 & 399 & 38.596 & $33.795-43.569$ \\
\hline Brusveen et al., 2008 & 52 & 115 & 45.217 & $35.918-54.769$ \\
\hline Chebel and Santos, 2010 & 126 & 318 & 39.623 & $34.209-45.232$ \\
\hline Colazo et al., 2013 & 38 & 119 & 31.933 & $23.686-41.103$ \\
\hline Colazo et al., 2013 & 52 & 122 & 42.623 & $33.716-51.896$ \\
\hline El-Zarkouny et al., 2004 & 145 & 310 & 46.774 & $41.113-52.498$ \\
\hline Fricke et al., 2014 & 131 & 331 & 39.577 & $34.272-45.070$ \\
\hline Giordano et al., 2015 & 513 & 1,210 & 42.397 & $39.592-45.238$ \\
\hline Gumen et al., 2012 & 66 & 118 & 55.932 & $46.499-65.060$ \\
\hline Herlihy et al., 2012 & 345 & 850 & 40.588 & $37.266-43.976$ \\
\hline Moreira et al., 2001 & 134 & 269 & 49.814 & $43.684-55.948$ \\
\hline Navanukraw et al., 2004 & 67 & 135 & 49.630 & $40.916-58.359$ \\
\hline Poock et al., 2015 & 680 & 1,790 & 37.989 & $35.734-40.283$ \\
\hline Rivera et al., 2010 & 141 & 399 & 35.338 & $30.647-40.249$ \\
\hline Rutigliano et al., 2008 & 85 & 260 & 32.692 & $27.025-38.760$ \\
\hline Souza et al., 2008 & 75 & 180 & 41.667 & $34.378-49.234$ \\
\hline Sterry et al., 2006 & 193 & 383 & 50.392 & $45.268-55.510$ \\
\hline $\begin{array}{l}\text { Stevenson et al., } 2012 \\
I^{2}=76.1 \%^{1}(P=0.0001)\end{array}$ & 35 & 105 & 33.333 & $24.433-43.201$ \\
\hline Total (fixed effects) & & 7,413 & 40.886 & $39.765-42.014$ \\
\hline Total (random effects) & & 7,413 & 41.690 & $39.185-44.217$ \\
\hline
\end{tabular}

${ }^{1} I^{2}=$ proportion of total variation of effect size estimates that is due to heterogeneity.

substantial heterogeneity $\left(I^{2}=83.3 \% ; P=0.0001\right)$ among the experimental groups regarding pregnancy loss.

In the onlyTAI group, 12 experimental groups were included, with 3,389 AI resulting in 1,393 pregnancies
(Table 7). The overall proportion of pregnancy loss was $9.6 \%(95 \% \mathrm{CI}=6.37-13.33)$ on $\mathrm{d} 60$ after $\mathrm{AI}$ for EDAI+TAI. There was substantial heterogeneity $\left(I^{2}=\right.$ $78.2 \% ; P=0.0001)$ among the experimental groups regarding pregnancy loss.

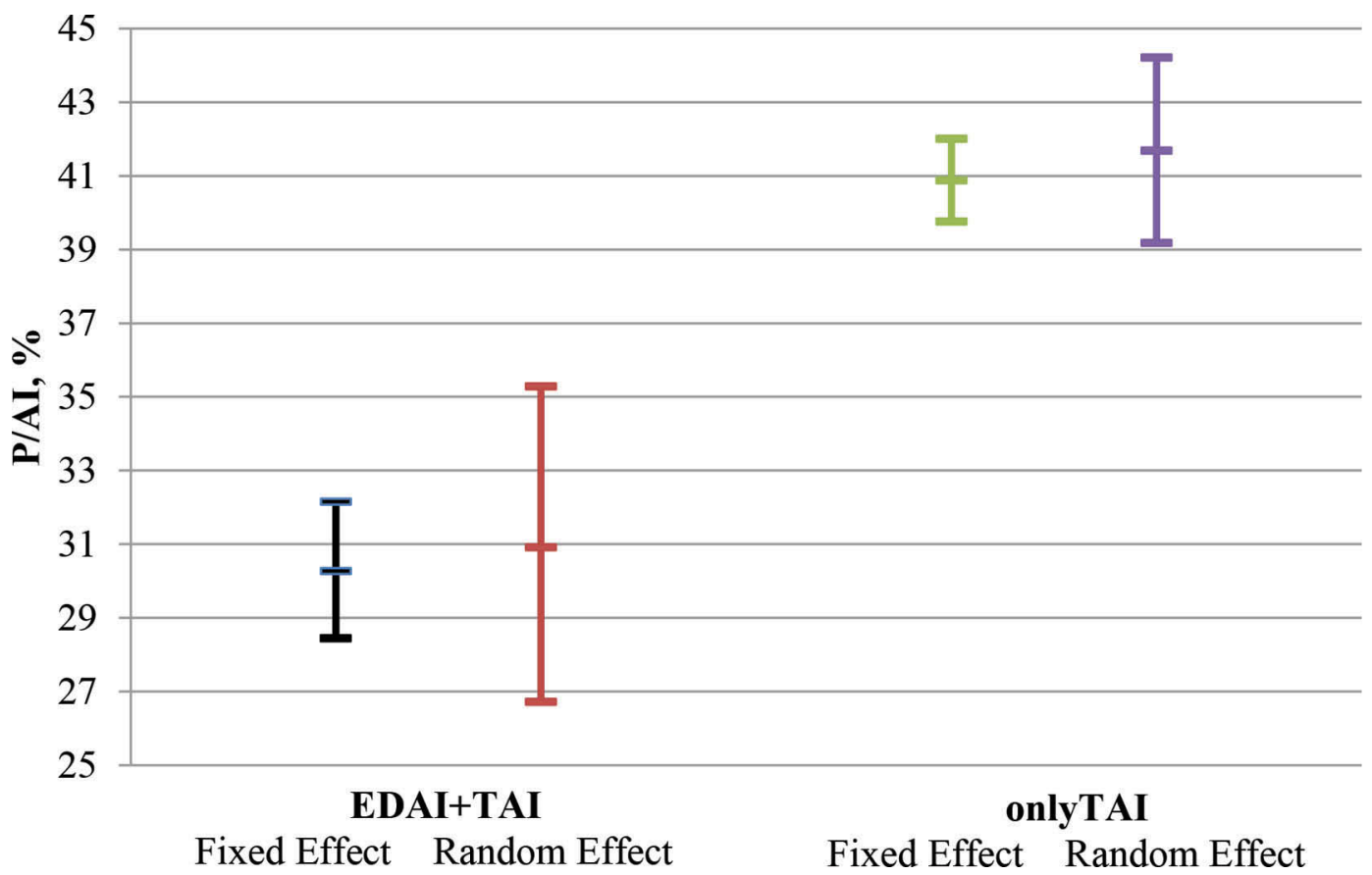

Figure 1. Overall proportion (95\% CI) of pregnancy per artificial insemination (P/AI) in 6 experimental groups with 2,400 AI using estrous detection and timed AI (left side; EDAI+TAI) and 18 experimental groups with 7,413 AI using only timed AI (right side; onlyTAI) during a Presynch-Ovsynch protocol for the first service under the fixed and the random effects models. Color version available online. 
Table 6. Proportion of pregnancy loss in 5 experimental groups including 1,811 AI and 593 pregnancies using estrous detection and timed AI (EDAI+TAI) in a Presynch-Ovsynch protocol for the first service

\begin{tabular}{lcccc}
\hline Reference & $\begin{array}{c}\text { No. of lost } \\
\text { pregnancies }\end{array}$ & $\begin{array}{c}\text { No. of } \\
\text { pregnancies }\end{array}$ & $\begin{array}{c}\text { Pregnancy } \\
\text { loss }(\%)\end{array}$ & $95 \%$ CI \\
\hline Bruno et al., 2013 & 10 & 188 & 5.319 & $2.580-9.564$ \\
Chebel and Santos, 2010 & 24 & 106 & 22.642 & $15.078-31.790$ \\
Chebel et al., 2006 & 17 & 98 & 17.347 & $10.442-26.315$ \\
Fricke et al., 2014 & 9 & 105 & 8.571 & $3.995-15.648$ \\
Gumen et al., 2012 & 7 & 96 & 7.292 & $2.982-14.448$ \\
$I^{2}=83.3 \%{ }^{1}(P=0.0001)$ & & 593 & 10.861 & $8.482-13.635$ \\
Total (fixed effects) & & 593 & 11.719 & $6.114-18.836$ \\
Total (random effects) & & &
\end{tabular}

${ }^{1} I^{2}=$ proportion of total variation of effect size estimates that is due to heterogeneity.

Based on the random effects model, we detected a numerical difference in pregnancy loss on d 60 between onlyTAI and EDAI+TAI of 2.1 percentage units $(9.6$ vs. $11.7 \%$ ). However, the $95 \%$ CI for the overall proportion of pregnancy loss for onlyTAI and EDAI+TAI were overlapping, indicating no difference.

\section{DISCUSSION}

The results from the present study indicate that incorporating estrous detection in a $\mathrm{PO}$ protocol for the first service impaired $\mathrm{P} / \mathrm{AI}$ and had no effect on pregnancy loss in lactating dairy cows.

Considering the 3 manuscripts (Chebel and Santos, 2010; Gumen et al., 2012; Fricke et al., 2014) with a randomized controlled study design, the odds of pregnancy evaluated on d 32 after AI in a PO protocol were $35 \%$ lower when cows were inseminated based on estrous detection and the remaining cows were timed AI (EDAI+TAI) compared with onlyTAI cows where cows were not observed for signs of estrus and only timed AI was performed. The proportion of cows inseminated after detected estrus ranged from 49.4 to $68.6 \%$ [58.9\% (189/321) in Chebel and Santos, 2010; 49.4\% (132/267) in Gumen et al., 2012; 68.6\% (230/335) in Fricke et al., 2014] in the 3 studies. Pregnancy per AI for cows inseminated after detected estrus ranged from 30.0 to $37.9 \%$ [32.3\% (61/189) in Chebel and Santos, 2010; $37.9 \%$ (50/132) in Gumen et al., 2012; $30.0 \%(68 / 230)$ in Fricke et al., 2014] and was numerically lower compared with cows receiving onlyTAI. In the studies, however, 3 different methods for estrous detection were used (i.e., tail painting, Kamar device, and automatic activity monitoring system, respectively). Fricke et al. (2014) also evaluated the effect of activity before the timed AI in the onlyTAI group. Cows with increased activity before timed AI were more likely to have increased progesterone concentration at the first $\mathrm{GnRH}$ injection (65 DIM) of the Ovsynch protocol compared with cows without increased activity (75 vs. 55\%). These cows also had numerically higher P/AI (41.4 vs. $35.3 \%$ ). This is in agreement with Chebel and Santos (2010), who observed that cyclic cows as determined by blood progesterone at 35, 49, and 62 DIM were more likely

Table 7. Proportion of pregnancy loss in 12 experimental groups including 3,389 AI and 1,393 pregnancies using only timed AI (onlyTAI) in a Presynch-Ovsynch protocol for the first service

\begin{tabular}{lcccc}
\hline Reference & $\begin{array}{c}\text { No. of lost } \\
\text { pregnancies }\end{array}$ & $\begin{array}{c}\text { No. of } \\
\text { pregnancies }\end{array}$ & $\begin{array}{c}\text { Pregnancy } \\
\text { loss (\%) }\end{array}$ & $95 \%$ CI \\
\hline Brusveen et al., 2008 & 1 & 50 & 2.000 & $0.506-10.647$ \\
Chebel and Santos, 2010 & 27 & 126 & 21.429 & $14.622-29.625$ \\
Colazo et al., 2013 & 2 & 38 & 5.263 & $0.644-17.749$ \\
Colazo et al., 2013 & 2 & 52 & 3.846 & $0.469-13.213$ \\
Fricke et al., 2014 & 4 & 131 & 3.053 & $0.838-7.633$ \\
Gumen et al., 2012 & 8 & 66 & 12.121 & $5.381-22.494$ \\
Herlihy et al., 2012 & 19 & 345 & 5.507 & $3.348-8.467$ \\
Moreira et al., 2001 & 15 & 134 & 11.194 & $6.402-17.790$ \\
Rivera et al., 2010 & 20 & 85 & 14.184 & $8.885-21.053$ \\
Rutigliano et al., 2008 & 17 & 190 & 20.000 & $12.104-30.079$ \\
Sterry et al., 2006 & 16 & 35 & 8.421 & $4.890-13.315$ \\
Stevenson et al., 2012 & 3 & & 8.571 & $1.804-23.058$ \\
$I^{2}=78.2 \%{ }^{1}$ (P $\left.=0.0001\right)$ & & 1,393 & 9.243 & $7.779-10.879$ \\
Total (fixed effects) & & 1,393 & 9.567 & $6.372-13.329$ \\
Total (random effects) & & &
\end{tabular}

${ }^{1} I^{2}=$ proportion of total variation of effect size estimates that is due to heterogeneity. 
to conceive after first AI. Therefore, the mechanism by which presynchronization with PGF may improve P/ AI seems to be limited to cycling cows. It is intended to manipulate the estrous cycle so that cows begin the Ovsynch protocol on d 5 to 9 resulting in a higher ovulation rate to the first $\mathrm{GnRH}$ and ultimately a higher P/AI after timed AI (Vasconcelos et al., 1999).

For the second approach, we included 24 experimental groups (total of $9,813 \mathrm{AI}$ ) that used a PO protocol with 2 injections of $\mathrm{PGF}_{2 \alpha} 14 \mathrm{~d}$ apart and an Ovsynch protocol for the timed AI. Although all of the included experimental groups in the second approach were from randomized clinical trials, the majority of them were not designed to compare the different approaches during a PO protocol (i.e., EDAI+TAI vs. onlyTAI) in a controlled manner. The populations included were rather cohorts from different manuscripts using the same protocol for presynchronization and were adequate to be included in our analysis. We labeled these studies observational because the allocation to EDAI+TAI or onlyTAI was not randomly controlled (Dohoo et al., 2009). Although meta-analyses have more commonly been used for combining results from randomized clinical trials, meta-analyses of observational studies are becoming more common and equally important $(\mathrm{Eg}-$ ger et al., 2001; Dickersin, 2002). However, results of a meta-analysis with observational studies need to be interpreted with caution because they are prone to a wide range of biases (Egger et al., 1998). Consequently, the focus should be an evaluation of heterogeneity among the studies. To improve homogeneity among the studies, we excluded studies using a PO protocol with timed AI protocols other than Ovsynch (e.g., Galvao et al., 2007; Chebel et al., 2010; Ribeiro et al., 2012). However, the proportion of between-study variation accounted for by heterogeneity was substantial for onlyTAI $\left(I^{2}=78.2 \%\right)$ and EDAI+TAI $\left(I^{2}=80.9 \%\right)$. The source of this high heterogeneity remains speculative. For example, the schedule of the Ovsynch protocol itself varied among the studies regarding the intervals between the $\mathrm{PGF}_{2 \alpha}$ and the second $\mathrm{GnRH}$ injection and between the second GnRH injection and the timed AI. Additionally, the interval between the second $\mathrm{PGF}_{2 \alpha}$ injection of the presynchronization and the onset of Ovsynch varied among the studies, ranging from 9 to $14 \mathrm{~d}$. This interval was shown to have an effect on P/ $\mathrm{AI}$ in a PO protocol (Galvao et al., 2007; Colazo et al., 2013). The exclusion of the study of Melendez et al. (2006) substantially improved homogeneity in the EDAI+TAI group. That trial was conducted in Mexico, with the majority of cows being not detected in estrus after a PO protocol receiving a timed AI. As speculated by Melendez et al. (2006), this population may have consisted predominantly of anovulatory cows, which were shown to have decreased $\mathrm{P} / \mathrm{AI}$ in a $\mathrm{PO}$ protocol (Chebel and Santos, 2010).

Nevertheless, the comparison of the overall proportion of $\mathrm{P} / \mathrm{AI}$ for onlyTAI and EDAI+TAI in approach 2 confirmed the results of approach 1 and our initial hypothesis. There was a difference of 10.8 percentage units in $\mathrm{P} / \mathrm{AI}$ favoring only TAI in a $\mathrm{PO}$ protocol.

Pregnancy loss on d 60 was not affected by the incorporation of insemination at detected estrus in a PO protocol. Although the statistical power in approach 1 was not adequate for detecting a considerable difference in pregnancy loss on d 60 between onlyTAI $(39 / 323)$ and EDAI+TAI (40/307), we also did not observe a fundamental difference in the overall proportion of pregnancy loss on d 60 when considering all the studies in approach 2 comparing onlyTAI and EDAI+TAI $(134 / 1,393$ vs. $67 / 593)$.

\section{CONCLUSIONS}

Based on a meta-analysis considering 20 manuscripts including 27 herds and 9,813 AI, we compared 2 management strategies for first service using a PO protocol. Cows with $100 \%$ TAI after completing a PO protocol had more $\mathrm{P} / \mathrm{AI}$ compared with cows that were inseminated after estrous detection or received TAI for cows showing no signs of estrus. The results of this meta-analysis are based on a large number of herds with different managerial conditions and seem to be applicable to high-producing dairy herds under confinement housing.

\section{REFERENCES}

Bicalho, R. C., S. H. Cheong, L. D. Warnick, and C. L. Guard. 2007. Evaluation of progesterone supplementation in a prostaglandin F2alpha-based presynchronization protocol before timed insemination. J. Dairy Sci. 90:1193-1200.

Borenstein, M., L. V. Hedges, J. P. Higgins, and H. R. Rothstein. 2009. Introduction to Meta-Analysis. Wiley, Chichester, UK.

Bruno, R. G., A. M. Farias, J. A. Hernandez-Rivera, A. E. Navarrette, D. E. Hawkins, and T. R. Bilby. 2013. Effect of gonadotropin-releasing hormone or prostaglandin F(2alpha)-based estrus synchronization programs for first or subsequent artificial insemination in lactating dairy cows. J. Dairy Sci. 96:1556-1567.

Brusveen, D. J., A. P. Cunha, C. D. Silva, P. M. Cunha, R. A. Sterry, E. P. Silva, J. N. Guenther, and M. C. Wiltbank. 2008. Altering the time of the second gonadotropin-releasing hormone injection and artificial insemination (AI) during Ovsynch affects pregnancies per AI in lactating dairy cows. J. Dairy Sci. 91:1044-1052.

Caraviello, D. Z., K. A. Weigel, P. M. Fricke, M. C. Wiltbank, M. J. Florent, N. B. Cook, K. V. Nordlund, N. R. Zwald, and C. L. Rawson. 2006. Survey of management practices on reproductive performance of dairy cattle on large US commercial farms. J. Dairy Sci. 89:4723-4735.

Chebel, R. C., M. J. Al-Hassan, P. M. Fricke, J. E. Santos, J. R. Lima, C. A. Martel, J. S. Stevenson, R. Garcia, and R. L. Ax. 2010. Supplementation of progesterone via controlled internal drug release inserts during ovulation synchronization protocols in lactating dairy cows. J. Dairy Sci. 93:922-931. 
Chebel, R. C., and J. E. Santos. 2010. Effect of inseminating cows in estrus following a presynchronization protocol on reproductive and lactation performances. J. Dairy Sci. 93:4632-4643.

Chebel, R. C., J. E. Santos, R. L. Cerri, H. M. Rutigliano, and R. G. Bruno. 2006. Reproduction in dairy cows following progesterone insert presynchronization and resynchronization protocols. J. Dairy Sci. 89:4205-4219.

Colazo, M. G., P. Ponce-Barajas, and D. J. Ambrose. 2013. Pregnancy per artificial insemination in lactating dairy cows subjected to 2 different intervals from presynchronization to initiation of Ovsynch protocol. J. Dairy Sci. 96:7640-7648.

DerSimonian, R., and N. Laird. 1986. Meta-analysis in clinical trials. Control. Clin. Trials 7:177-188.

Dickersin, K. 2002. Systematic reviews in epidemiology: Why are we so far behind? Int. J. Epidemiol. 31:6-12

Dohoo, I. R., S. W. Martin, and H. Stryhn. 2009. Veterinary Epidemiologic Research. 2nd ed. University of Prince Edward Island, Charlottetown, PEI, Canada.

Egger, M., M. Schneider, and G. Davey Smith. 1998. Spurious precision? Meta-analysis of observational studies. BMJ 316:140-144.

Egger, M., G. Smith, and D. G. Altman. 2001. Systematic Reviews in Health Care. Meta-analysis in context. BMJ Books, London, UK.

El-Zarkouny, S. Z., J. A. Cartmill, B. A. Hensley, and J. S. Stevenson. 2004. Pregnancy in dairy cows after synchronized ovulation regimens with or without presynchronization and progesterone. J. Dairy Sci. 87:1024-1037.

Ferguson, J. D., and A. Skidmore. 2013. Reproductive performance in a select sample of dairy herds. J. Dairy Sci. 96:1269-1289.

Freeman, M. F., and J. W. Tukey. 1950. Transformation related to the angular and the square root. Ann. Math. Stat. 21:607-611.

Fricke, P. M., J. O. Giordano, A. Valenza, G. Lopes Jr., M. C. Amundson, and P. D. Carvalho. 2014. Reproductive performance of lactating dairy cows managed for first service using timed artificial insemination with or without detection of estrus using an activitymonitoring system. J. Dairy Sci. 97:2771-2781.

Galvão, K. N., M. F. Sa Filho, and J. E. Santos. 2007. Reducing the interval from presynchronization to initiation of timed artificial insemination improves fertility in dairy cows. J. Dairy Sci. 90:4212-4218

Giordano, J. O., M. L. Stangaferro, R. Wijma, W. C. Chandler, and R. D. Watters. 2015. Reproductive performance of dairy cows managed with a program aimed at increasing insemination of cows in estrus based on increased physical activity and fertility of timed artificial inseminations. J. Dairy Sci. 98:2488-2501.

Gumen, A., A. Keskin, G. Yilmazbas-Mecitoglu, E. Karakaya, A. Alkan, H. Okut, and M. C. Wiltbank. 2012. Effect of presynchronization strategy before Ovsynch on fertility at first service in lactating dairy cows. Theriogenology 78:1830-1838.

Herlihy, M. M., J. O. Giordano, A. H. Souza, H. Ayres, R. M. Ferreira, A. Keskin, A. B. Nascimento, J. N. Guenther, J. M. Gaska, S. J. Kacuba, M. A. Crowe, S. T. Butler, and M. C. Wiltbank. 2012. Presynchronization with Double-Ovsynch improves fertility at first postpartum artificial insemination in lactating dairy cows. J. Dairy Sci. 95:7003-7014.

Higgins, J. P., S. G. Thompson, J. J. Deeks, and D. G. Altman. 2003. Measuring inconsistency in meta-analyses. BMJ 327:557-560.

Melendez, P., G. Gonzalez, E. Aguilar, O. Loera, C. Risco, and L. F. Archbald. 2006. Comparison of two estrus-synchronization proto- cols and timed artificial insemination in dairy cattle. J. Dairy Sci. 89:4567-4572

Moreira, F., C. Orlandi, C. A. Risco, R. Mattos, F. Lopes, and W. W. Thatcher. 2001. Effects of presynchronization and bovine somatotropin on pregnancy rates to a timed artificial insemination protocol in lactating dairy cows. J. Dairy Sci. 84:1646-1659.

Navanukraw, C., D. A. Redmer, L. P. Reynolds, J. D. Kirsch, A. T. Grazul-Bilska, and P. M. Fricke. 2004. A modified presynchronization protocol improves fertility to timed artificial insemination in lactating dairy cows. J. Dairy Sci. 87:1551-1557.

Poock, S. E., W. R. Lamberson, and M. C. Lucy. 2015. Effect of different gonadorelin $(\mathrm{GnRH})$ products used for the first or resynchronized timed artificial insemination on pregnancy rates in postpartum dairy cows. Theriogenology 84:504-508.

Pursley, J. R., M. O. Mee, and M. C. Wiltbank. 1995. Synchronization of ovulation in dairy cows using PGF2alpha and GnRH. Theriogenology 44:915-923.

Ribeiro, E. S., A. P. Monteiro, F. S. Lima, H. Ayres, R. S. Bisinotto, M. Favoreto, L. F. Greco, R. S. Marsola, W. W. Thatcher, and J. E. Santos. 2012. Effects of presynchronization and length of proestrus on fertility of grazing dairy cows subjected to a 5-day timed artificial insemination protocol. J. Dairy Sci. 95:2513-2522.

Rivera, F., C. Narciso, R. Oliveira, R. L. Cerri, A. Correa-Calderon, R. C. Chebel, and J. E. Santos. 2010. Effect of bovine somatotropin $(500 \mathrm{mg}$ ) administered at ten-day intervals on ovulatory responses, expression of estrus, and fertility in dairy cows. J. Dairy Sci. 93:1500-1510.

Rutigliano, H. M., F. S. Lima, R. L. Cerri, L. F. Greco, J. M. Vilela, V. Magalhaes, F. T. Silvestre, W. W. Thatcher, and J. E. Santos. 2008. Effects of method of presynchronization and source of selenium on uterine health and reproduction in dairy cows. J. Dairy Sci. 91:3323-3336.

Souza, A. H., H. Ayres, R. M. Ferreira, and M. C. Wiltbank. 2008. A new presynchronization system (Double-Ovsynch) increases fertility at first postpartum timed AI in lactating dairy cows. Theriogenology 70:208-215.

Sterry, R. A., M. L. Welle, and P. M. Fricke. 2006. Treatment with gonadotropin-releasing hormone after first timed artificial insemination improves fertility in noncycling lactating dairy cows. J. Dairy Sci. 89:4237-4245.

Stevenson, J. S., and A. P. Phatak. 2005. Inseminations at estrus induced by presynchronization before application of synchronized estrus and ovulation. J. Dairy Sci. 88:399-405.

Stevenson, J. S., S. L. Pulley, and H. I. Mellieon Jr. 2012. Prostaglandin F2alpha and gonadotropin-releasing hormone administration improve progesterone status, luteal number, and proportion of ovular and anovular dairy cows with corpora lutea before a timed artificial insemination program. J. Dairy Sci. 95:1831-1844.

Vasconcelos, J. L., R. W. Silcox, G. J. Rosa, J. R. Pursley, and M. C. Wiltbank. 1999. Synchronization rate, size of the ovulatory follicle, and pregnancy rate after synchronization of ovulation beginning on different days of the estrous cycle in lactating dairy cows. Theriogenology 52:1067-1078.

Wiltbank, M. C., and J. R. Pursley. 2014. The cow as an induced ovulator: Timed AI after synchronization of ovulation. Theriogenology $81: 170-185$ 